\title{
2D and 3D Power Doppler Ultrasound of Endometrium as Implantation Marker
}

\author{
${ }^{1}$ Luis T Mercé, ${ }^{2}$ María J Barco, ${ }^{1}$ Santiago Bau \\ ${ }^{1}$ International Ruber Hospital, Madrid, Spain \\ ${ }^{2}$ Bolonia Gynecological Medical Center, Zaragoza, Spain
}

Correspondence: Luis T. Mercé, International Ruber Hospital. Madrid. Spain

e-mail: Itmerce@sego.es

\begin{abstract}
Transvaginal ultrasonography has an important role in assessing the endometrium. With 2DUS, a single measurement of endometrial thickness in the sagittal plane is widely used in assisted reproductive technology and in pregnancy prediction. Endometrial volume, measured with 3DUS, has been studied as a potentially more accurate parameter. The endometrial pattern was related to the likelihood of implantation. This pattern correlated in a positive fashion with subsequent implantation. 3D ultrasound and 3D power Doppler parameters have been applied to assisted reproductive techniques as outcome predictors, although studies are still scarce, they show very promising results.
\end{abstract}

Key words: Two-dimensional ultrasound/Power Doppler/ Endometrium/Implantation marker

\section{INTRODUCTION}

Assessment of the endometrium by ultrasound is of great interest for a better management of reproductive technologies. This is true for two reasons. First, the success of the embryo transfer procedure is conditioned by the intrinsic embryo quality and endometrial receptivity. And second, it has been proposed that ultrasound and Doppler parameters would properly evaluate endometrial receptivity. Therefore, ultrasound and Doppler of the endometrium become clinical markers of implantation.

Up to now, bi-dimensional (2D) ultrasound enabled us to measure two endometrial markers of implantation: the thickness and the morphological pattern. Actually pulsed and color Doppler made possible the study of endometrial and uterine perfusion involved in the implantation process.

New perspectives for the study of the endometrium as an implantation marker are now open with the advent of threedimensional (3D) ultrasound and Doppler. 3D volumetry allows a more accurate endometrial measurement as it has been before. In a similar way, 3D power Doppler gives us information about the number of endometrial vessels and the blood flow through them. In advance, these variables are much more precise than Doppler velocimetry to assess endometrial perfusion. This is the time to see our expectances and hopes fulfilled, and if this undeniable technological advance will be a diagnostic improvement of implantation markers.

\section{TWO-DIMENSIONAL ULTRASOUND AND DOPPLER OF THE ENDOMETRIUM}

The main implantation ultrasound markers are the endometrial thickness and its morphological pattern. The endometrial color mapping and the vascular resistance of the spiral and radial arteries are used for the study of endometrial perfusion.

\section{Endometrial Thickness}

Endometrial thickness is the maximum distance between the echogenic myoendometrial interfaces measured in the longitudinal axis (Figs 1A and B). It is a simple and reproducible measurement that has proved a good intra and inter-observer agreement. ${ }^{1}$

Endometrial thickness is independent of the ovarian stimulation protocol ${ }^{2}$ with no significant differences between the hCG administration day and the embryo transfer day. ${ }^{3}$ Nonetheless it has been advised to perform several measurements to avoid the variability (from 1.3 to $2.8 \mathrm{~mm}$ ) due to uterine contractions. ${ }^{4}$

In assisted reproductive technology there is no significant difference between the endometrial thickness of conceptional ( $\mathrm{n}=514$; 8.6-11.8 mm) and non-conceptional cycles ( $\mathrm{n}=1110$; 8.6-11.9 mm). ${ }^{5}$ However, in conceptional cycles an accelerated endometrial growth during the luteal phase is detected, reaching significant differences 14 days after the day of oocyte retrieval., 6

In pregnancy prediction, endometrial thickness shows a highly negative predictive value (87-100\%) but, with a lot of false positives. ${ }^{5}$ Anyway the endometrium is non-receptive when its thickness is less than $7 \mathrm{~mm}$ at the hCG administration day. An endometrial thickness greater than $14 \mathrm{~mm}^{8}$ is also a poor prognostic factor, but this is not shared by all authors. ${ }^{9}$ 

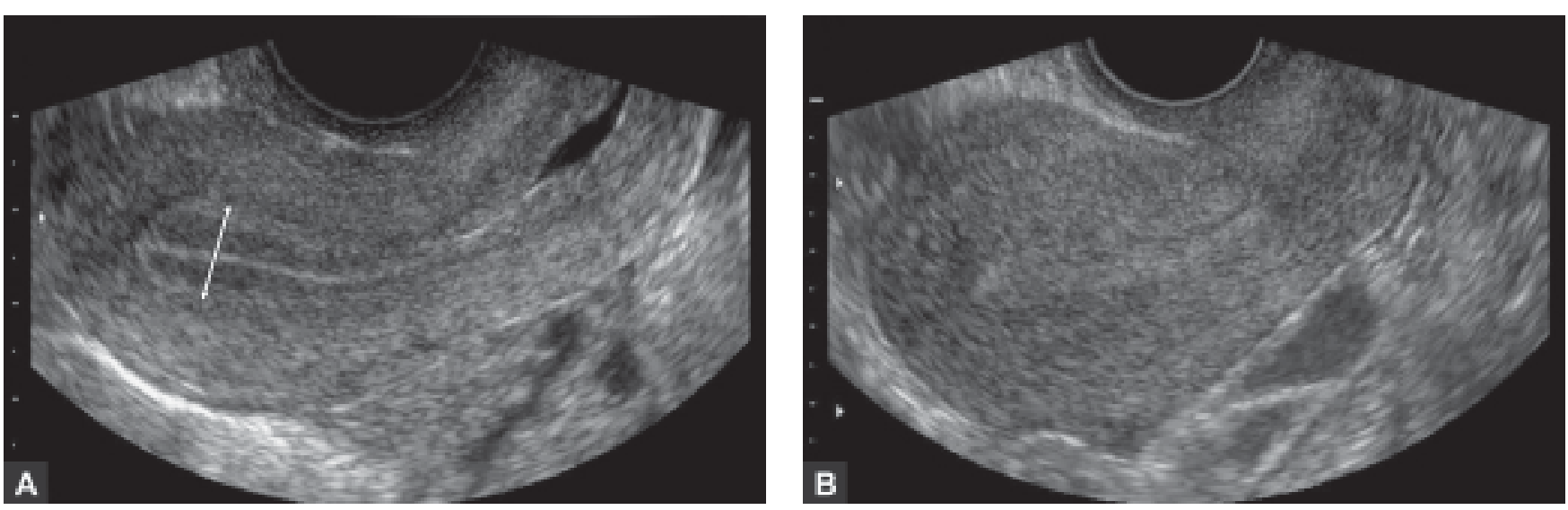

Figs 1A and B: Measurement of endometrial thickness and echogenicity patterns: $(A)$ Multilayered proliferative endometrium or "triple line" pattern and (B) Endometrium non-multilayered

In an oocyte donation program with hormone replacement treatment it has been demonstrated that pregnancy rates decrease as endometrial thickness decreases. When endometrial thickness is equal or greater than $9 \mathrm{~mm}$ a pregnancy rate of $68 \%$ is reached, and reduces to $20 \%$ with endometrium lesser than $6 \mathrm{~mm} .{ }^{10}$ Although it is possible to achieve conception with an endometrium thinner than $4 \mathrm{~mm},{ }^{11}$ this is a poor prognostic factor and will warrant a further endometrial study. ${ }^{10}$

In our study group on 40 IVF cycles we found that more than $50 \%$ of the endometrium had a thickness of 11 to $15 \mathrm{~mm}$ and showed a pregnancy rate higher than $50 \%$. Thicker than this the pregnancy rate decreases, but not significantly. With endometrium thinner than $9 \mathrm{~mm}$ there were no pregnancies. And only a $12.5 \%$ of gestations were achieved with an endometrial thickness between 9 and $11 \mathrm{~mm}$ (Table 1).

Table 1: Pregnancy rate according to endometrial thickness on the day hCG administration in 40 IVF cycles

\begin{tabular}{lll}
\hline $\begin{array}{l}\text { Endometrial } \\
\text { thickness }\end{array}$ & $\begin{array}{c}\text { No cases } n \\
(\%)\end{array}$ & $\begin{array}{c}\text { Pregnancy rate } n \\
(\%)\end{array}$ \\
\hline$<9 \mathrm{~mm}$ & $2(5 \%)$ & $0(0 \%)$ \\
$9-11 \mathrm{~mm}$ & $8(20 \%)$ & $1(12.5 \%)$ \\
$11-15 \mathrm{~mm}$ & $21(52.5 \%)$ & $11(52.4 \%)$ \\
$>15 \mathrm{~mm}$ & $9(22.5 \%)$ & $4(44.4 \%)$ \\
\hline
\end{tabular}

\section{Endometrial Pattern}

The endometrial pattern is the relative echogenicity showed by the endometrium with respect to the adjacent myometrium. Its importance as implantation marker is based in that it reflects the histological development. ${ }^{12}$

Up to four patterns of endometrial echogenicity have been described. ${ }^{13}$ However, a "triple line" endometrium will be adequate as an implantation marker ${ }^{14}$ (Fig. 1). This endometrial pattern appears unchanged after any ovarian stimulation protocol and by the hormonal replacement treatment before embryo transfer. ${ }^{15}$ No significant differences in the morphological endometrial pattern have been found between the hCG day and the transfer day either. ${ }^{3}$

The "triple line" endometrium is the parameter that best reflects the endometrial receptivity, whereas a "non-triple line" pattern is associated frequently to non-pregnancy cycles. ${ }^{5}$ Like the endometrial thickness, the "triple line" pattern has a high false positive rate. Despite this, it can be useful as negative predictive factor (NPV $=75-100 \%$ ).

The implantation and pregnancy rates decrease progressively as the myometrial echogenicity increases, measured on the day of hCG administration. ${ }^{7,16}$ Therefore, there is an inverse relationship between the endometrial echogenicity degree and the pregnancy chance. Although it is possible to achieve a pregnancy with a "non-triple line" pattern the probability is very low. ${ }^{15}$

According our results the "non-triple line" endometrium (20\%, 8/40) showed a lower pregnancy rate (37.5\%) compared to that of "triple line" (68.5\%). Some authors consider better to combine thickness and endometrial pattern as endometrial predictors. ${ }^{9}$ In our cases all gestations achieved with a "nontriple line" endometrium had a thickness greater than $11 \mathrm{~mm}$.

\section{Doppler of the Endometrium}

Endometrial Doppler should reflect more appropriately the endometrial perfusion and uterine receptivity because the endometrium is the place where implantation occurs. ${ }^{17}$

The Doppler study of the endometrial spiral arteries and subendometrial radial arteries (Fig. 2) proved a decreased resistance on the oocyte retrieval day ${ }^{18}$ and on the embryo transfer day ${ }^{19}$ when pregnancy is achieved. 


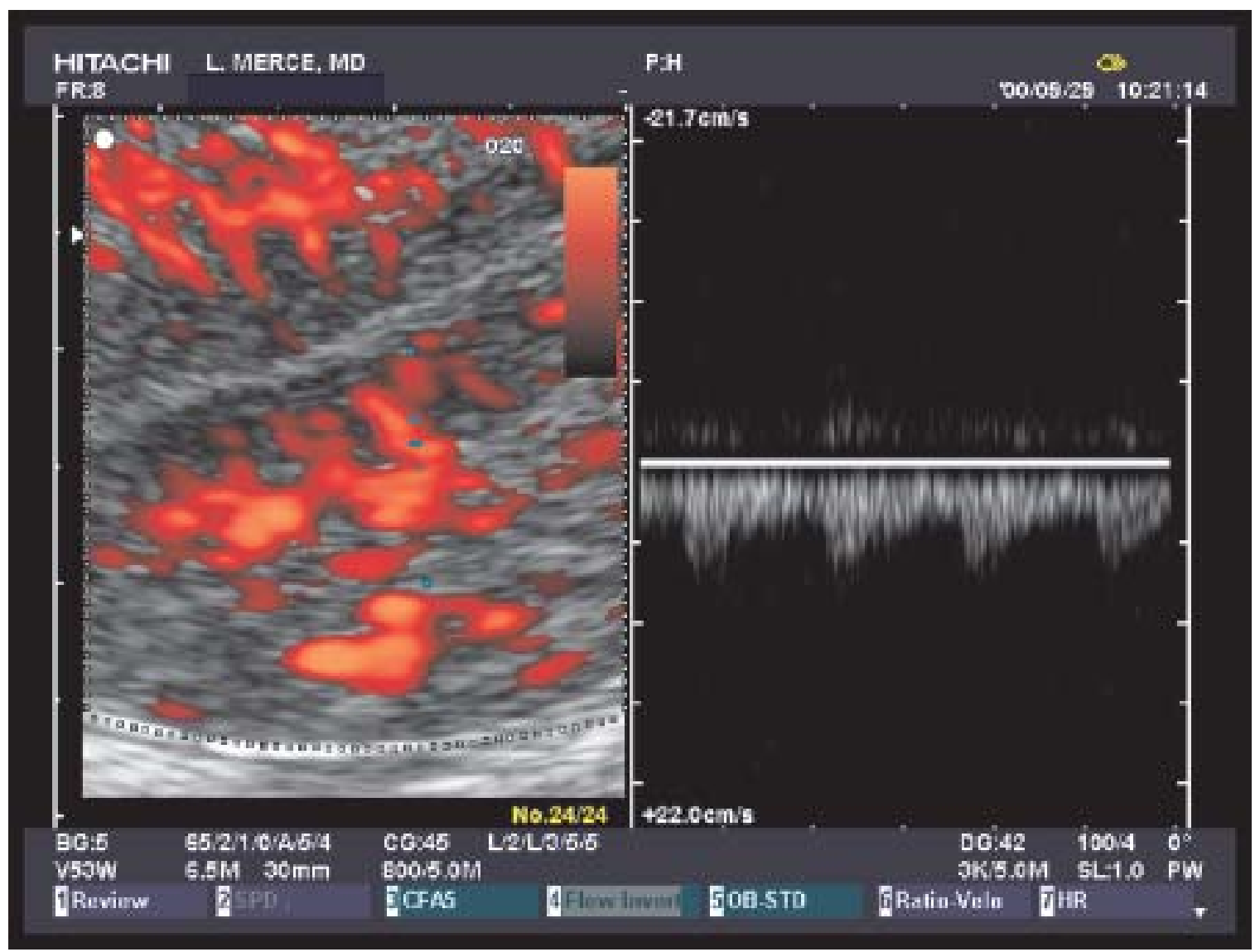

Fig. 2: Flow velocity waveform of subendometrial-endometrial artery on hCG administration day

Using color ${ }^{19-21}$ or power Doppler ${ }^{17}$ four types of endometrial mapping have been established: Type 0 or negative flow when only surrounding myometrial vessels are seen without reaching the endometrium; Type I or peripheral flow if the Doppler signal reaches the hyperechogenic endometrial outer layer; Type II or intermediate flow when color mapping occupies the outer half of the endometrial hypoechogenic thickness; and type III or central flow, if the vessels arrive to the endometrial cavity invading all the endometrial thickness (Figs 3A to D). Power Doppler is advisable for two reasons: to detect the signal from vessels with low velocity blood flow and to avoid the signal loss due to a $90^{\circ}$ angle incidence of the ultrasound beam associated to conventional color Doppler. ${ }^{17}$

The absence of an endometrial and myometrial subendometrial color mapping means a complete failure ${ }^{20}$ or significant decrease $\mathrm{e}^{22,23}$ of implantation, whereas the pregnancy rate increases when the vessels reach the subendometrial halo and the endometrium. ${ }^{20,22}$ In a study of more than 600 cycles evaluated by color Doppler on the embryo transfer day it was found that implantation and pregnancy rates were $24.2 \%$ and
47.8\% respectively when endometrial and subendometrial flow was detected; $15.8 \%$ and $29.7 \%$ if only subendometrial flow was detected and $3.5 \%$ and $7.5 \%$ when neither subendometrial nor endometrial flow were registered. ${ }^{22}$ Women with a great endometrial flow area as measured by power Doppler have a greater pregnancy probability, whereas below $5 \mathrm{~mm}^{2}$ it is very difficult to achieve implantation despite a good endometrial thickness. ${ }^{24}$

On 40 cycles of IVF we have found that more than $70 \%$ of cases have an endometrial flow type I or II the day of hCG administration and in this group the pregnancy rate is $38 \%$. However, it is more interesting to confirm that the pregnancy rate increases progressively as vascularization rises, reaching a $67 \%$ when the color signal reaches the center of the endometrium (Table 2).

When a pregnancy is achieved in absence of endometrial and subendometrial flow, on the day of embryo transfer, more than a half of these pregnancies will finish as spontaneous miscarriage, ${ }^{22}$ suggesting that the development of the endometrial vascular tree is very important in the support of the initial stages of gestation. 

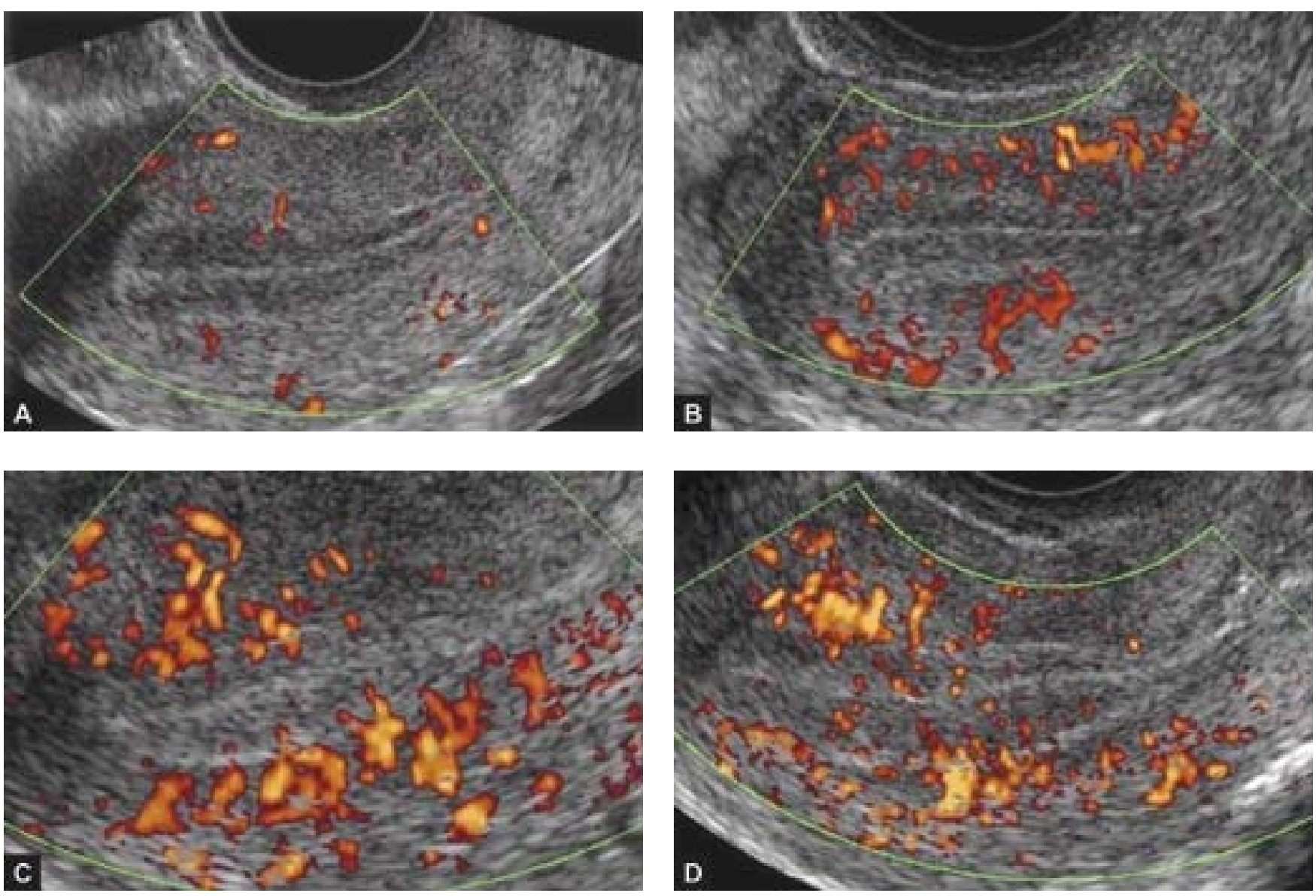

Figs 3A to D: Endometrial amplitude mapping: (A) Type 0, only myometrial vessels can be seen without reaching the subendometrial halo; (B) Type I, color signal reaches the hyperechogenic outer layer of the endometrium; (C) Type II, color mapping occupies the outer half of the endometrial hypoechogenic thickness; and (D) Type III color reaches the endometrial cavity invading the entire endometrial thickness

Table 2: Pregnancy rate according to endometrial blood flow type on the day hCG administration in 40 IVF cycles

\begin{tabular}{lll}
\hline $\begin{array}{l}\text { Endometrial } \\
\text { blood flow }\end{array}$ & $\begin{array}{c}\text { No cases } n \\
(\%)\end{array}$ & $\begin{array}{c}\text { Pregnancy rate } n \\
(\%)\end{array}$ \\
\hline Type 0 & $5(12.5 \%)$ & $1(20 \%)$ \\
Type I & $17(42.5 \%)$ & $6(35 \%)$ \\
Type II & $12(30 \%)$ & $5(42 \%)$ \\
Type III & $6(15 \%)$ & $4(67 \%)$ \\
\hline
\end{tabular}

\section{THREE-DIMENSIONAL ULTRASOUND AND POWER DOPPLER OF THE ENDOMETRIUM}

Three-dimensional ultrasound has a remarkable methodological advantage that is the simultaneous assessment of the endometrial volume and its perfusion. After displaying the endometrial volume and its vessels through 3D power Doppler angiography, a program named VOCAL (Virtual Organ Computer-aided
Analysis) is applied to calculate the endometrial perfusion by applying three power Doppler indices. ${ }^{25}$ The vascularization index (VI) measures the number of color voxels in the endometrial volume, representing the number of endometrial vessels expressed as a percentage. The flow index (FI) is the average color value in all color voxels, meaning the average intensity of endometrial blood flow. The vascularization flow index (VFI) is the average value of the color in all gray and color voxels of the endometrial volume, expressing this way the vascularization as well as the flow of the endometrium (Fig. 4).

\section{Endometrial Volume}

Although the endometrial volume can be assessed by bidimensional ultrasound, three-dimensional ultrasound is the only procedure that permits a reliable calculation. ${ }^{26}$

The endometrial volume measurement is very reproducible by 3-D ultrasound ${ }^{27,28}$ being even more reproducible than the 


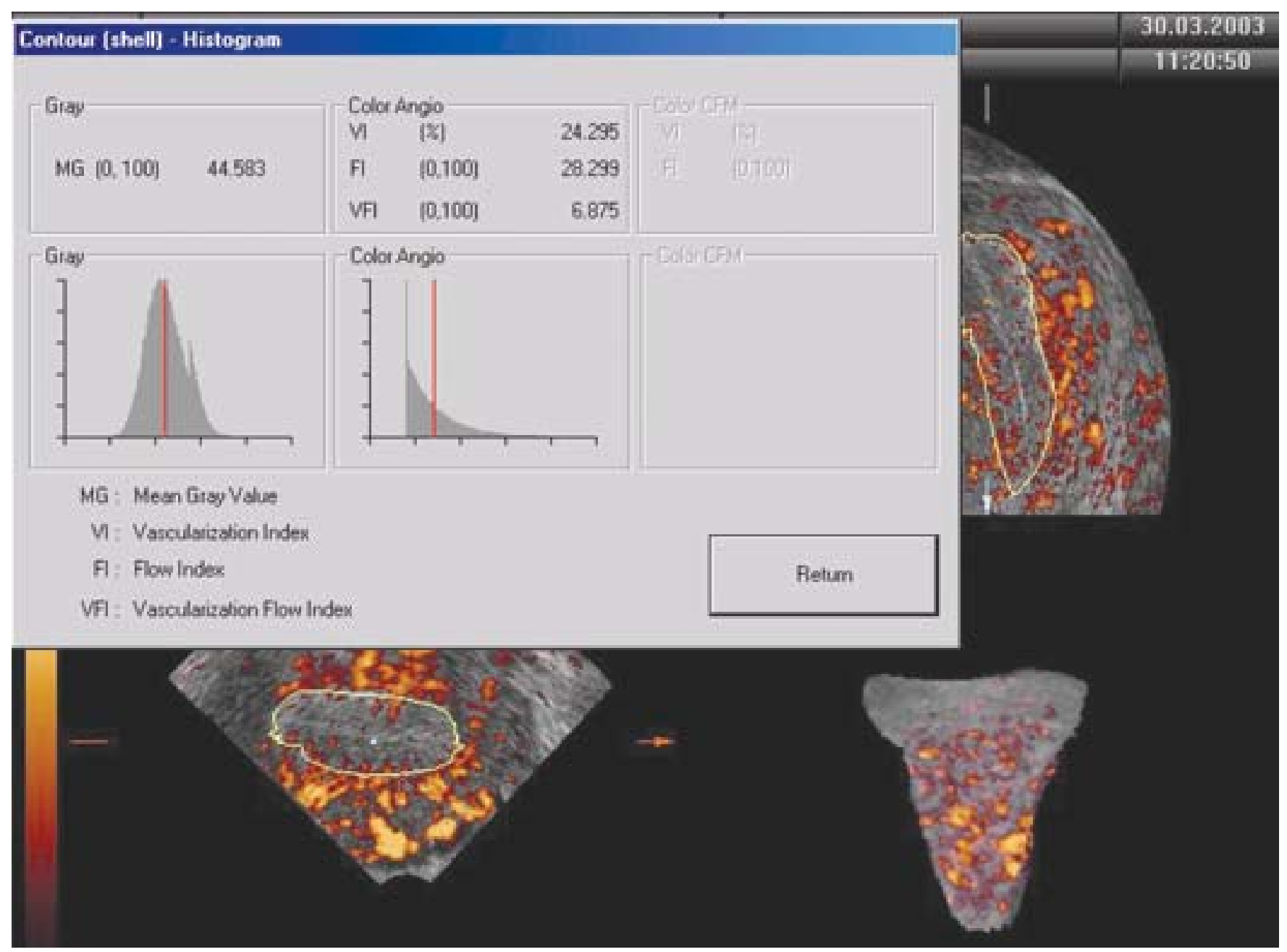

Fig. 4: Three-dimensional power Doppler indices of the endometrium obtained by VOCAL software . $\mathrm{VI}$ : vascularization index; FI: flow index; VFI: vascularization flow index

measurement of endometrial thickness. ${ }^{29,30}$ The best reproducibility is achieved by the rotational method with a rotation step of less than $30^{\circ 30}$ and a minimum of 12 planes using the VOCAL software. ${ }^{31}$ A rotation angle inferior to $30^{\circ}$ is associated to coefficients of variation less than $1 \%$ and intraclass correlation coefficients greater than $0.94 .^{30}$

This technique has been recently validated by comparing the volume of several objects measured in different ways, with their actual volume measured using a water displacement technique. ${ }^{32}$ All the methods applied (conventional and rotational angles of $30^{\circ}, 15^{\circ}, 9^{\circ}$ and $6^{\circ}$ in $\mathrm{B}$ and $\mathrm{C}$ planes) resulted highly reliable by showing differences inferior to $4 \%$ over the real volume and intra-class correlation coefficients (ICC) greater than 0.99 . However, the measurements performed with rotations of $6^{\circ}$ and $9^{\circ}$ were significantly more reliable than those calculated with an angle of $30^{\circ}$ or with the conventional technique. The authors advise the use of a rotation of $9^{\circ}$ since it is as reliable as the $6^{\circ}$ but significantly faster in its acquisition. There are no significant differences neither between two observers nor the different measurement planes. ${ }^{32}$

From the above mentioned facts, we evaluated the reproducibility of the endometrial volume calculated with $3 \mathrm{D}$ ultrasound, by comparing the volume acquisition from A and $\mathrm{C}$ planes applying rotations of $15^{\circ}$ and $9^{\circ}$. This distinction was considered of importance because the volume acquisition is usually made from a longitudinal uterine section (plane A) although the plane $\mathrm{C}$ is advised for volume calculation. On the other hand, $15^{\circ}$ (12 planes) and $9^{\circ}$ (20 planes) seem to be the most reproducible rotational angles. Twenty five patients under ovarian stimulation with gonadotrophins for intrauterine insemination (11 patients) or in vitro fertilization (14 patients) have been studied in this way. Endometrial volumes were obtained from a longitudinal uterine section on the day of hCG administration. Two consecutive volumes were acquired with 
Table 3: Intraobserver differences (mean and SD), intra-class correlation coefficient and repeatability coefficient of the endometrial volume according to plane $(A$ and $C)$ and degrees $\left(15^{\circ}\right.$ and $\left.9^{\circ}\right)$ with VOCAL imaging program $(n=50)$

\begin{tabular}{|c|c|c|c|c|c|c|}
\hline \multicolumn{2}{|c|}{$E V$} & \multirow{2}{*}{$\begin{array}{l}\text { Mean difference } \\
0.06\end{array}$} & \multirow{2}{*}{$\frac{S D}{0.43}$} & \multirow{2}{*}{$\frac{I C C}{0.98}$} & \multirow{2}{*}{$\frac{95 \% \text { CI }}{0.96-0.99}$} & \multirow{2}{*}{$\frac{r}{2.64}$} \\
\hline A Plane & $15^{\circ}$ & & & & & \\
\hline & $9^{\circ}$ & -0.07 & 0.50 & 0.97 & 0.94-0.99 & 0.98 \\
\hline \multirow[t]{2}{*}{ C Plane } & $15^{\circ}$ & -0.08 & 0.65 & 0.97 & 0.93-0.99 & 1.26 \\
\hline & $9^{\circ}$ & -0.11 & 0.49 & 0.98 & 0.96-0.99 & 0.96 \\
\hline
\end{tabular}

EV: Endometrial volume; ICC: Intra-class correlation coefficient; SD: standard deviation; r: repeatability coefficient (1.96 $\times \sqrt{2}$ within - subject variance)

a five minutes interval, gathering a total of 50 endometrial volumes. The results are on Table 3. Intra-class correlation coefficients are similar for both planes and for the different rotational steps and show a high reliability of the technique (0.93-0.99). The repeatability coefficient (“r”) or the maximum difference probably to occur among repeated measurements is inferior using a $9^{\circ}$ angle for any of the planes (plane A: 0.98; plane C: 0.96), although " $\mathrm{r}$ " is only slightly different from the calculated using a $15^{\circ}$ for the C plane (1.26). In the A plane, using $15^{\circ}$, the measurement shows a higher repeatability coefficient. After these results, we performed an estimate of the endometrial volume with the VOCAL programme using a $9^{\circ}$ rotational step regardless of the longitudinal or coronal plane (Fig. 5).

The relationship between the uterine and endometrial volume shows a good correlation to the day of the menstrual cycle. ${ }^{33}$ Nonetheless, the value of this measurement has proven to be more interesting as a clinical marker of pituitary suppression and uterine receptivity in the assisted reproductive techniques.

Firstly, the available results suggest that the endometrial volume calculated by 3D ultrasound is an adequate parameter

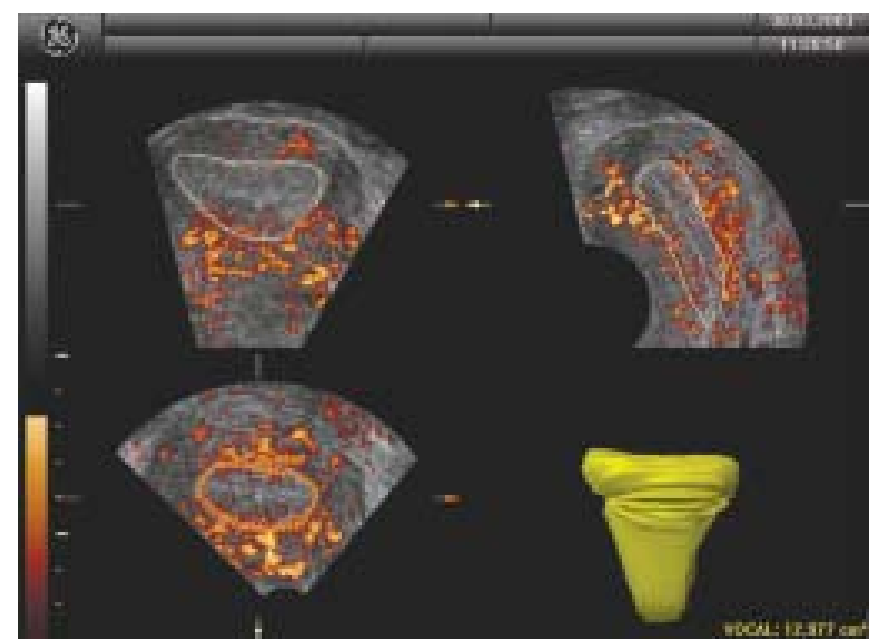

Fig. 5: Assessment of endometrial volume with VOCAL software. We use the coronal plane and 9 degrees by showing better reproducibility to diagnose the pituitary suppression and non-suppression after the administration of GnRH agonists in IVF cycles. ${ }^{34,35}$ However it is preferable to choose a different threshold for the diagnosis of suppression (as defined by a serum estradiol concentrations $<150 \mathrm{pmol} / \mathrm{L}$ or $40 \mathrm{pg} / \mathrm{ml})$ than the nonsuppression (serum estradiol concentrations $>150 \mathrm{pmol} / \mathrm{L}$ or $40 \mathrm{pg} / \mathrm{ml}$ ). An endometrial volume inferior to $1.48 \mathrm{ml}$ identifies the $92 \%$ of suppressed patients but only the $42 \%$ of suppression failures, whereas a volume $>0.50 \mathrm{ml}$ detects the $90 \%$ of nonsuppressions. The endometrial volume has turned to be superior to the endometrial thickness only when non-suppression is evaluated. $^{35}$

The implantation and pregnancy indices were previously demonstrated to be significantly lower when the endometrial volume is less than $2 \mathrm{ml}$ and no pregnancy is achieved when it is inferior to $1 \mathrm{ml}^{36}$ The difficulty to obtain a pregnancy with endometrial volumes greater than $8 \mathrm{ml}$ has also been communicated. ${ }^{37}$ Other authors find no relationship between the endometrial volume and the pregnancy rate in an IVF program. ${ }^{38,39}$ When this parameter was applied in an intrauterine insemination program, an endometrial volume less than $2 \mathrm{ml}$ in the day of intrauterine insemination was demonstrated to have a significantly smaller pregnancy probability $(6 \%)$ when compared to patients with greater volumes (22\%). ${ }^{40}$

Our experience on 40 IVF cycles appears on Table 4. A $10 \%$ of women had a endometrial volume inferior to $3 \mathrm{ml}$ and in these cases no pregnancy was achieved. Nearly a half of the cases developed a volume from 3 to $6 \mathrm{ml}$ with a pregnancy rate of $41 \%$. Finally, a third of the patients had a volume greater than $7 \mathrm{ml}$ with a pregnancy rate of $50 \%$. In the entire study group the pregnancy rate reached the $40 \%(16 / 40)$. These results confirm the difficulty to obtain a pregnancy when the

Table 4: Pregnancy rate according to endometrial volume on the day hCG administration in 40 IVF cycles

\begin{tabular}{lll}
\hline $\begin{array}{l}\text { Endometrial } \\
\text { volume }\end{array}$ & $\begin{array}{c}\text { No cases } n \\
(\%)\end{array}$ & $\begin{array}{c}\text { Pregnancy rate } n \\
(\%)\end{array}$ \\
\hline$<3 \mathrm{ml}$ & $4(10 \%)$ & $0(0 \%)$ \\
$3-6 \mathrm{ml}$ & $22(55 \%)$ & $9(40.9 \%)$ \\
$>7 \mathrm{ml}$ & $14(35 \%)$ & $7(50 \%)$ \\
\hline
\end{tabular}


endometrial volume is smaller than $3 \mathrm{ml}$ and show some linear relationship between the increase of the volume and the easiness to get a pregnancy.

\section{THREE-DIMENSIONAL DOPPLER INDICES OF ENDOMETRIAL PERFUSION}

Very few studies have evaluated the reproducibility of 3D Doppler indices in the assessment of the vascularization and perfusion of the endometrium. ${ }^{41}$ The intra and inter-observer reliability to assess the endometrial and subendometrial perfusion is very high showing intra-class correlation coefficients greater to 0.985 . Only the subendometrial flow index shows reliability significantly smaller, although exceptionally high. ${ }^{41}$

We have also obtained an adequate reproducibility of endometrial (Table 5) and subendometrial Doppler indices (Table 6), although with ICC lower than those previously

Table 5: Intraobserver differences (mean and SD), intra-class correlation coefficient and repeatability coefficient of the endometrial 3D Doppler indices according to plane $(A$ and $C)$ and degrees $\left(15^{\circ}\right.$ and $\left.9^{\circ}\right)$ with VOCAL imaging program $(n=50)$

\begin{tabular}{|c|c|c|c|c|c|c|c|}
\hline & Doppl & indices & Mean difference & $S D$ & ICC & $95 \% C I$ & $r$ \\
\hline \multirow[t]{4}{*}{ EVI } & A plane & $15^{\circ}$ & -1.26 & 5.24 & 0.91 & $0.81-0.96$ & 10.35 \\
\hline & & $9^{\circ}$ & -1.00 & 4.10 & 0.94 & $0.87-0.97$ & 8.11 \\
\hline & C plane & $15^{\circ}$ & -1.92 & 4.95 & 0.92 & 0.83-0.96 & 10.23 \\
\hline & & $9^{\circ}$ & -1.63 & 4.42 & 0.94 & $0.86-0.97$ & 9.07 \\
\hline \multirow[t]{4}{*}{ EFI } & A plane & $15^{\circ}$ & -0.43 & 2.01 & 0.68 & $0.40-0.85$ & 3.96 \\
\hline & & $9^{\circ}$ & -0.23 & 2.08 & 0.63 & $0.32-0.82$ & 4.03 \\
\hline & C plane & $15^{\circ}$ & -0.21 & 2.01 & 0.70 & $0.43-0.86$ & 3.88 \\
\hline & & $9^{\circ}$ & -0.35 & 2.16 & 0.66 & $0.37-0.84$ & 4.21 \\
\hline \multirow[t]{4}{*}{ EVFI } & A plane & $15^{\circ}$ & -0.38 & 1.66 & 0.90 & 0.78-0.95 & 3.28 \\
\hline & & $9^{\circ}$ & -0.28 & 1.29 & 0.93 & $0.85-0.97$ & 2.54 \\
\hline & C plane & $15^{\circ}$ & -0.53 & 1.60 & 0.90 & $0.80-0.96$ & 3.25 \\
\hline & & $9^{\circ}$ & -0.40 & 1.52 & 0.91 & $0.82-0.96$ & 3.02 \\
\hline
\end{tabular}

EVI: Endometrial vascularization index; EFI: Endometrial fIow index; EVFI: Endometrial vascularization flow index; ICC: Intra-class correlation coefficient; SD: standard deviation; r: repeatability coefficient $(1.96 \times \sqrt{ } 2$ within - subject variance).

Table 6: Intraobserver differences (mean and SD), intra-class correlation coefficient and repeatability coefficient of the subendometrial 3D Doppler indices according to plane (A and C) and degrees $\left(15^{\circ}\right.$ and $\left.9^{\circ}\right)$ with VOCAL imaging program $(n=50)$

\begin{tabular}{|c|c|c|c|c|c|c|c|}
\hline \multicolumn{3}{|c|}{ Doppler indices } & \multirow{2}{*}{$\begin{array}{l}\text { Mean difference } \\
-2.32\end{array}$} & \multirow{2}{*}{$\frac{S D}{8.79}$} & \multirow{2}{*}{$\frac{I C C}{0.84}$} & \multirow{2}{*}{$\frac{95 \% \text { CI }}{0.66-0.92}$} & \multirow{2}{*}{$\frac{r}{17.48}$} \\
\hline SEVI & A plane & $15^{\circ}$ & & & & & \\
\hline & & $9^{\circ}$ & -0.30 & 6.45 & 0.93 & $0.84-0.97$ & 12.40 \\
\hline & C plane & $15^{\circ}$ & -3.01 & 5.39 & 0.95 & $0.88-0.98$ & 11.92 \\
\hline & & $9^{\circ}$ & -1.92 & 4.32 & 0.97 & 0.93-0.99 & 9.11 \\
\hline \multirow[t]{4}{*}{ SEFI } & A plane & $15^{\circ}$ & -0.34 & 3.40 & 0.73 & $0.48-0.87$ & 6.56 \\
\hline & & $9^{\circ}$ & -0.09 & 2.29 & 0.86 & $0.72-0.94$ & 4.41 \\
\hline & C plane & $15^{\circ}$ & -0.77 & 2.67 & 0.80 & $0.60-0.91$ & 5.35 \\
\hline & & $9^{\circ}$ & -0.73 & 2.11 & 0.88 & $0.75-0.95$ & 4.30 \\
\hline \multirow[t]{4}{*}{ SEVFI } & A plane & $15^{\circ}$ & -0.75 & 3.56 & 0.86 & $0.71-0.94$ & 6.99 \\
\hline & & $9^{\circ}$ & 0.37 & 3.03 & 0.92 & $0.83-0.97$ & 5.86 \\
\hline & C plane & $15^{\circ}$ & -1.06 & 2.43 & 0.94 & $0.87-0.97$ & 5.11 \\
\hline & & $9^{\circ}$ & -0.67 & 1.86 & 0.97 & 0.93-0.99 & 3.81 \\
\hline
\end{tabular}

SEVI: Subendometrial vascularization index; SEFI: Subendometrial fIow index; SEVFI: Subendometrial vascularization flow index; ICC: Intra-class correlation coefficient; SD: standard deviation; r: repeatability coefficient (1.96 $\times \sqrt{2}$ within-subject variance). 
published. In a more comprehensive way we observed that the endometrial as well as the subendometrial vascularization (defined as an outer layer of $2 \mathrm{~mm}$ around the myoendometrial interface) are more reproducible in plane $\mathrm{C}$ and with a $9^{\circ}$ rotational step than it is when 20 planes from the coronal plane are evaluated. However, some details must be analyzed.

The endometrial vascularization index is more reproducible on the A plane with rotation of $9^{\circ}($ ICC $=0.94$ and $r=8.11)$ whereas the subendometrial vascularization index is more reproducible in the plane $\mathrm{C}$ with $9^{\circ}$, showing the highest ICC (0.97) and the lower repeatability coefficient (9.11). The endometrial vascularization flow index has the greater ICC (0.94) and the smaller " $\mathrm{r}$ " coefficient (2.54) on the A plane with $9^{\circ}$, while the subendometrial VFI is more reproducible on the $\mathrm{C}$ plane (ICC $=0.97$ and $\mathrm{r}=3.81$ ).

The higher repeatability coefficients belong to the vascularization index while the lower ICC is showed by the flow index. These results are in agreement with previous findings about endometrial and ovarian vascularization assessment by three-dimensional power Doppler. ${ }^{42}$ The endometrial flow index shows only an ICC of 0.70 on the plane $C$ with $15^{\circ}$, being lower for the other options. It is worth remembering that as a general rule an ICC above 0.70 is considered acceptable. ${ }^{43}$ The best subendometrial flow index is observed for the $\mathrm{C}$ plane with $9^{\circ}$ (ICC $=0.88$ and $r=4.30$ ).

The first reported results, applying 3D power Doppler indices on the first day of ovarian stimulation as predictors of IVF cycle outcome, concluded that the subendometrial flow index is an important prognostic factor of the success of the treatment. ${ }^{25}$ Nonetheless the results were surprisingly quite the opposite of what we expected. That is, the conception cycles showed vascularization, flow and vascularization flow indices significantly lower than those of non-conceptional cycles. According to other authors, a better functional status of the endometrium after $\mathrm{GnRh}$ agonist treatment would be expressed by low 3D power Doppler indices, increasing the possibility of a successful implantation. ${ }^{25}$

The vascularization flow index on the hCG administration day has proved to be a good pregnancy predictor in IVF cycles, being superior to the endometrial volume, flow index and vascularization index. A VFI above 0.24 showed a sensitivity of $83.3 \%$ and a specificity of $88.9 \%$, PPV of $93.8 \%$ and NPV of $72.3 \%$. The pregnancy rate was $33 \%(18 / 54) .{ }^{44}$ When the subendometrial flow is studied on the transfer day a significantly high FI was found in the group of patients that got pregnant ${ }^{37}$ (Fig. 6).

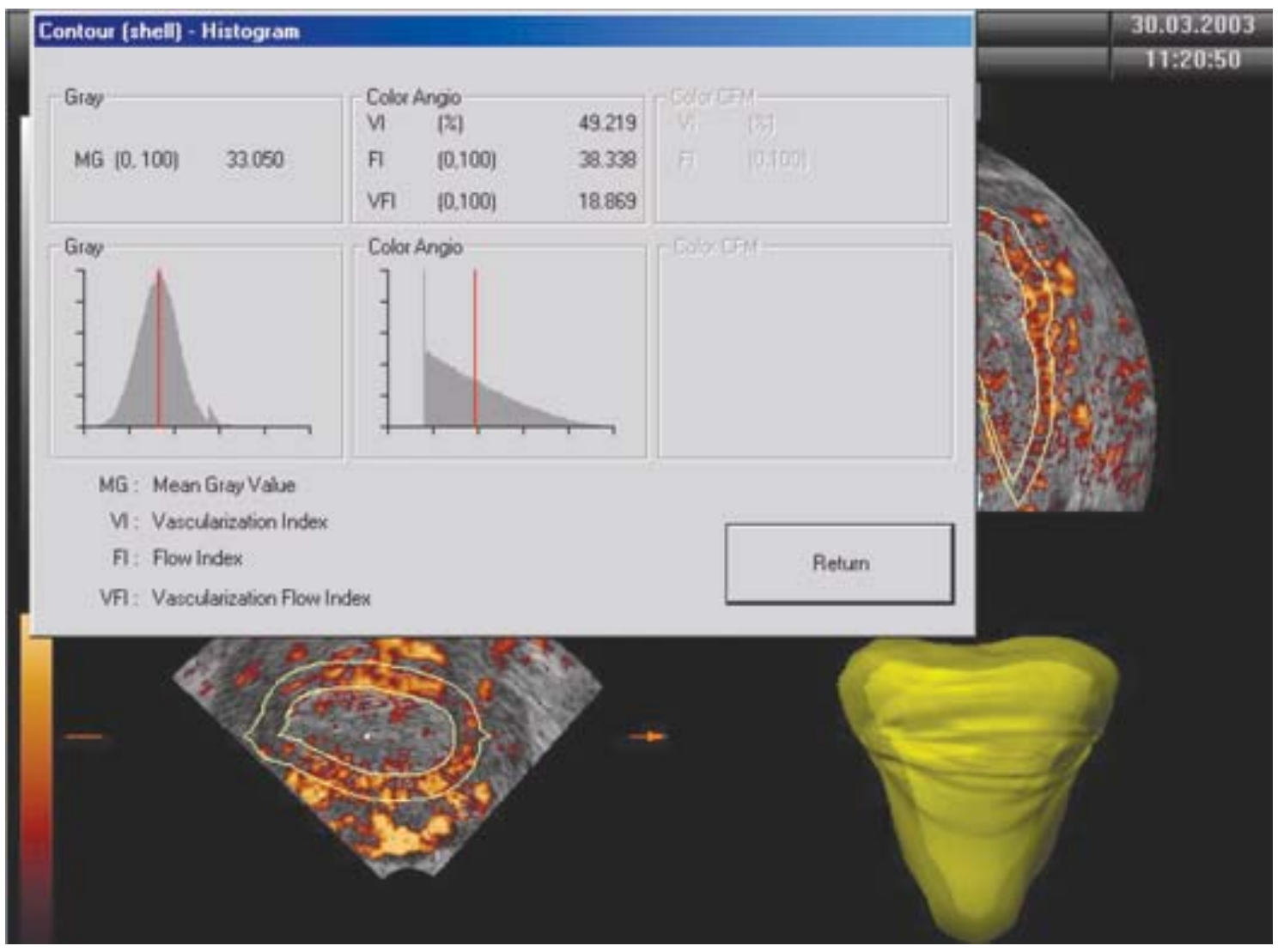

Fig. 6: Subendometrial three-dimensional power Doppler indices on the hCG day in IVF cycle 
2D and 3D Power Doppler Ultrasound of Endometrium as Implantation Marker

Table 7: Pregnancy rate according to subendometrial 3D power Doppler indices on the day of hCG administration in 40 IVF cycles

\begin{tabular}{llll}
\hline Doppler indices & & No cases $n(\%)$ & Pregnancy rate $n(\%)$ \\
\hline Vascularization & $<10$ & $5(12.5 \%)$ & $0(0 \%)$ \\
& $10-35$ & $18(45 \%)$ & $11(61.1 \%)$ \\
& $>35$ & $17(42.5 \%)$ & $5(29.4 \%)$ \\
& $<28$ & $12(30 \%)$ & $1(8.3 \%)$ \\
Flow & $28-34$ & $20(50 \%)$ & $12(60 \%)$ \\
& $>34$ & $8(20 \%)$ & $3(37.5 \%)$ \\
Vascularization-Flow & $6-12$ & $10(25 \%)$ & $1(10 \%)$ \\
& $>12$ & $17(42.5 \%)$ & $10(58.8 \%)$ \\
\hline
\end{tabular}

Our results evaluating the subendometrial flow the day of hCG administration in 40 IVF cycles appear on Table 7. In general the intermediate values of vascularization, flow and vascularization flow indices show the best outcomes and are present in the $40-50 \%$ of patients. Another interesting finding is that below a vascularization index of 10 there is no pregnancy which happens in the $12.5 \%$ of patients. When blood flow is very high, as measured by any of the indices, the pregnancy rate is lower although differences are not significant.

Finally, we assessed jointly the endometrial volume and Doppler indices in an attempt to find a better predictive factor of the success of the technique. The best combination is achieved with the vascularization index (Table 8). When the endometrial volume is below $3 \mathrm{ml}$ or the vascularization index is less than 10 which occurs in the $30 \%$ of patients, no pregnancy is achieved. On the contrary, an exceptionally favorable situation appears when the endometrial development is above $7 \mathrm{ml}$ with an subendometrial VI between 10 and 35\%. In these cases $(6 / 40 ; 15 \%)$, the pregnancy rate is very high (5/6 cases; 83\%). In a $25 \%$ of cycles we found an intermediate endometrial development (from 3 to $6 \mathrm{ml}$ ) with an intermediate vascularization index as well (10 to 35$)$. In these cycles the pregnancy rate is $60 \%$, above the average pregnancy rate which was $40 \%$ (16/40). For any endometrial thickness superior to 3 ml showing a subendometrial vascularization greater than $35 \%$, the pregnancy rate falls below the mean down to $31 \%$.

In summary, we reviewed the morphological and vascular endometrial markers of implantation. We have dedicated special attention to the earliest results offered by 3D ultrasound and power Doppler angiography. This technique allows the assessment of the volume and vascularization of the endometrium at the same time which implies an important methodological advance. The literature results as well as ours demonstrate a good reproducibility of the technique. Nonetheless it is convenient to point that although the 3D power Doppler indices seem to reflect the vascular density
Table 8: Pregnancy rate according to endometrial volume and subendometrial vascularization index on the day of hCG administration in 40 IVF cycles

\begin{tabular}{lll}
\hline Parameters & No cases n (\%) & Pregnancy rate $n(\%)$ \\
\hline $\mathrm{EV}<3 \mathrm{ml} \mathrm{o} \mathrm{VI}<10$ & $8(20 \%)$ & $0(0 \%)$ \\
$\mathrm{EV}>3 \mathrm{ml}+\mathrm{VI}>35$ & $16(40 \%)$ & $5(31.2 \%)$ \\
$\mathrm{EV} 3-6 \mathrm{ml}+\mathrm{VI} 10-35$ & $10(25 \%)$ & $6(60 \%)$ \\
$\mathrm{EV}>7 \mathrm{ml}+\mathrm{VI} 10-35$ & $6(15 \%)$ & $5(83.3 \%)$ \\
\hline
\end{tabular}

(vascularization index), the blood flow (flow index) and the tissue perfusion (vascularization flow index), its exact relationship with the real blood flow is not fully demonstrated. ${ }^{45}$ A recent study has demonstrated a good correlation between the "fractional moving blood volume" as a technique to quantify power Doppler and the real perfusion of sheep adrenal glands as evaluated by radioactive micro spheres. ${ }^{46}$ As a conclusion, when 3D ultrasound and 3D power Doppler parameters have been applied to assisted reproductive techniques as outcome predictors, although studies are still scarce, they show very promising results. Obviously we need larger prospective studies showing the real predictive value and clinical applicability of this technique for daily practice.

\section{REFERENCES}

1. Spandorfer SD, Arredondo-Soberon F, Loret de Mola JR, Feinberg RF. Realibility of intraobserver and interobserver sonographic endometrial strip thickness measurements. Fertil Steril 1998;10:152-54.

2. Imoedemhe DA, Shaw RW, Kirkland A, Chan R. Ultrasound measurement of endometrial thickness on different ovarian stimulation regimens during in vitro fertilization. Hum Reprod 1987;2:545-47.

3. Khalifa E, Brzyski RG, Oehninger S, Acosta AA, Muasher SJ. Sonographic appearance of the endometrium: the predictive 
value for the outcome of in vitro fertilization in stimulated cycles. Hum Reprod 1992;7:677-80.

4. Dastidar KG, Dastidar SG. Dynamics of endometrial thickness over time: a reappraisal to standardize ultrasonographic measurements in a infertility program. Fertil Steril 2003;80:21315.

5. Friedler S, Schenker JG, Herman A, Lewin A. The role of ultrasonography in the evaluation of endometrial receptivity following assisted reproduction treatments: a critical review. Hum Reprod Update 1996;2:323-35.

6. Rabinowitz R, Laufer N. Lewin A, Navot D, Bar I, Margalioth EJ, Schenker JJ. The value of endometrial measurement in the prediction of pregnancy following in vitro fertilization. Fertil Steril 1986;45: 824-28.

7. Leibovitz Z, Grinin V, Rabia R, Degani S, Shapiro I, Tal J et al. Assessment of endometrial receptivity for gestation in patients undergoing in vitro fertilization, using endometrial thickness and the endometrium-myometrium relative echogenicity coefficient. Ultrasound Obstet Gynecol 1999;14:194-99.

8. Weissman A, Gotlieb L, Casper RF. The detrimental effect of increased endometrial thickness on implantation and pregnancy rates and outcome in an in vitro fertilization program. Fertil Steril 1999;1:147-49.

9. Dietterich C, Check JH, Choe JK, Nazari A, Lurie D. Increased endometrial thickness on the day of human chorionic gonadotropin injection does not adversely affect pregnancy or implantation rates following in vitro fertilization-embryo transfer. Fertil Steril 2002;77:781-86.

10. Noyes N, Hampton BS, Berkeley A, Licciardi F, Grifo J, Krey L. Factors useful in predicting the success of oocyte donation: a 3-year retrospective analysis. Fertil Steril 2001;76:92-97.

11. Sundstrom P. Establishment of a successful pregnancy following in vitro fertilization with a endometrial thickness of no more than 4 mm. Hum Reprod 1998;13:1550-52.

12. Grunfeld L, Walker B, Bergh PA, Sandler B, Hofmann G, Navot D. High-resolution endovaginal ultrasonography of the endometrium: a non-invasive test for endometrial adequacy. Obstet Gynecol 1991;78:200-04.

13. Smith B, Porter R, Ahuja K, Craft I. Ultrasonic assessment of endometrial changes in stimulated cycles an in vitro fertilization and embryo transfer program. J In Vitro Fertil Embryo Transf 1984;1:233-38.

14. Sher G, Herbert C, Maassarani G, Jacobs MH. Assessment of the late proliferative phase endometrium by ultrasonography in patients undergoing in vitro fertilization and embryo transfer (IVF/ET). Hum Reprod 1991;6:232-37.

15. Tan SL, Biljan MM. Selection of candidates for in vitro fertilization based on color Doppler findings. In Kupesic S, De Ziegler D (Eds): Ultrasound and Infertility. London: The Parthenon Publishing Group 2000;155-68.

16. Fanchin R, Righini C, Ayoubi JM, Olivennes F, de Ziegler D, Frydman R. New look at endometrial echogenicity: objective computer-assisted measurements predict endometrial receptivity in in vitro fertilization-embryo transfer. Fertil Steril 2000;74:27481.
17. Mercé LT. Ultrasound markers of implantation. Ultrasound Rev Obstet Gynecol 2002;2:110-23.

18. Kupesic S, Bekavac I, Bjelos D, Kurjak A. Assessment of endometrial receptivity by transvaginal color Doppler and threedimensional power Doppler ultrasonography in patients undergoing in vitro fertilization procedures. J Ultrasound Med 2001;20:125-34.

19. Battaglia C, Artini PG, Giulini S, Salvatori M, Maxia N, Petraglia F et al. Colour Doppler changes and thromboxane production after ovarian stimulation with gonadotrophin-releasing hormone agonist. Human Reprod 1997;11:2477-82.

20. Zaidi J, Campbell S, Pittrof R, Tan SL. Endometrial thickness, morphology, vascular penetration and velocimetry in predicting implantation in an in vitro fertilization program. Ultrasound Obstet Gynecol 1995;6:191-98.

21. Applebaum M. The Menstrual Cycle, Menopause, Ovulation Induction, an In Vitro fertilization. In: Copel JA, Reed KL. Doppler Ultrasound in Obstetrics and Gynecology. New York: Raven Press 1995;71-86.

22. Chien LW, Au HK, Chen PL, Xiao J, Tzeng CR. Assessment of uterine receptivity by the endometrial-subendometrial blood flow distribution pattern in women undergoing in vitro fertilizationembryo transfer. Fertil Steril 2002;78:245-51.

23. Maugey-Laulom B, Commenges-Ducos M, Jullien V, Papaxanthos-Roche A, Scotet V, Commenges D. Endometrial vascularity and ongoing pregnancy after IVF. Eur J Obstet Gynecol Reprod Biol 2002;104:137-43.

24. Yang J-H, Wu M-Y, Chen C-D, Jiang M-C, Ho H-N, Yang Y$\mathrm{S}$. Association of endometrial blood flow as determined by a modified colour Doppler technique with subsequent outcome of in vitro fertilization. Hum Reprod 1999;14:1606-10.

25. Schild RL, Holthaus S, d'Alquen J, Fimmers R, Dorn C, van der Ven H, Hansmann M. Quantitative assessment of subendometrial blood flow by three-dimensional-ultrasound is an important predictive factor of implantation in an in vitro fertilization programme. Hum Reprod 2000;15:89-94.

26. Riccabona M, Nelson TR, Pretorius DH. Three dimensional ultrasound, accuracy of distance and volume measurements. Ultrasound Obstet Gynecol 1996;8:588-91.

27. Kyei-Mensah A, Maconochie N, Zaidi J, Pittrof R, Shaker A, Campbell S, Tan SL. Transvaginal three-dimensional ultrasound: reproducibility of ovarian and endometrial volume measurements. Fertil Steril 1996;66:718-22.

28. Yaman C, Sommergruber M, Ebner T, Polz W, Moser M, Tews G. Reproducibility of transvaginal three-dimensional endometrial volume measurements during ovarian stimulation. Hum Reprod 1999;14:2604-8.

29. Yaman C, Ebner T, Jesacher K, Obermayr G, Polz W, Tews G. Reproducibility of three-dimensional ultrasound endometrial volume measurements in patients with postmenopausal bleeding. Ultrasound Obstet Gynecol 2002; 19: 282-86.

30. Raine-Fenning N, Campbell B, Collier J, Brincat M, Johnson I. The reproducibility of endometrial volume acquisition and measurement with the VOCAL-imaging program. Ultrasound Obstet Gynecol 2002;19:69-75. 
31. Bordes A, Bory AM, Benchaib M, Rudigoz RC, Salle B. Reproducibility of transvaginal three-dimensional endometrial volume measurements with virtual organ computer-aided analysis (VOCAL) during ovarian stimulation. Ultrasound Obstet Gynecol 2002; 19:76-80.

32. Raine-Fenning NJ, Clewes JS, Kendall NR, Bunkheila AK, Campbell BK, Johnson IR. The interobserver reliability and validity of volume calculation from three-dimensional ultrasound datasets in the in vitro setting. Ultrasound Obstet Gynecol 2003;21:283-91.

33. Lee A, Sator M, Kratochwil A, Deutinger J, Vytiska-Binsdorfer E, Bernaschek G. Endometrial volume change during spontaneous menstrual cycles: volumetry by transvaginal threedimensional ultrasound. Fertil Steril 1997;68:831-35.

34. Yaman C, Ebner T, Sommergruber M, Hartl J, Polz W, Tews G. Three-dimensional endometrial volume estimation as a predictor of pituitary down-regulation in an IVF-embryo transfer programme. Hum Reprod 2000;15:1698-702.

35. Child TJ, Sylvestre C, Tan SL. Endometrial volume and thickness measurements predict pituitary suppression and non-suppression during IVF. Hum Reprod 2002;17:3110-13.

36. Raga F, Bonilla-Musoles F, Casañ EM, Klein O, Bonilla F. Assessment of endometrial volume by three-dimensional ultrasound prior to embryo transfer: clues to endometrial receptivity. Hum Reprod 1999;14:2851-54.

37. Kupesic S, Bekavac I, Bjelos D, Kurjak A. Assessment of endometrial receptivity by transvaginal color Doppler and threedimensional power Doppler ultrasonography in patients undergoing in vitro fertilization procedures. J Ultrasound Med 2001;20:125-34.

38. Schild RL, Indefrei D, Eschweiller S, van der Ven H, Fimmers $\mathrm{R}$, Hansmann M. Three-dimensional endometrial volume calculation and pregnancy rate in an in vitro fertilization programme. Hum Reprod 1999;14:1255-58.
39. Schild RL, Knobloch C, Dorn C, Fimmers R, Van der Ven H, Hansmann M. Endometrial receptivity in an in vitro fertilization program as assessed by spiral artery blood flow, endometrial thickness, endometrial volume, and uterine artery blood flow. Fertil Steril 2001;75:361-66.

40. Zollner U, Zollner KP, Blissing S, Pohls U, Steck T, Dietl J, Muller T. Impact of three-dimensionally measured endometrial volume on the pregnancy rate after intrauterine insemination. Zentral Gynakol 2003;125:136-41.

41. Raine-Fenning NJ, Campbell BK, Clewes JS, Kendall NR, Johnson IR. The reliability of virtual organ computer-aided analysis (VOCAL) for the semiquantification of ovarian, endometrial and subendometrial perfusion. Ultrasound Obstet Gynecol 2003;22:633-39.

42. Jarvela IY, Sladkevicius, Tekay AH, Campbell S, Nargund G. Intraobserver and interobserver variability of ovarian volume, gray-scale and color flow indices obtained using transvaginal three-dimensional power Doppler ultrasonography. Ultrasound Obstet Gynecol 2003;21:277-82.

43. Burdok EI, Fleiss JL, Haresty AS. A new view of interobserver agreement . Pers Psychol 1963;16:373-84.

44. Wu HM, Chiang CH, Huang HY, Chao AS, Wang HS, Soong YK. Detection of the subendometrial vascularization blood flow by three-dimensional ultrasound may be useful for predicting the pregnancy rate for patients undergoing in vitro fertilizationembryo transfer. Fertil Steril 2003;79:507-11.

45. Deane C. Placing values on pictures: what information is there in color flow images and how can we use it?. Ultrasound Obstet Gynecol 2001;17:189-90.

46. Hernández-Andrade E, Jansson T, Ley D, Bellander M, Persson M, Lingman G, Marsál K. Validation of fractional moving blood volume measurement with power Doppler ultrasound in an experimental sheep model. Ultrasound Obstet Gynecol 2004;23:363-8. 